Article

\title{
Strengthening Professional Efficacy Due to Sustainable Development of Social and Individual Competences-Empirical Research Study among Polish and Slovak Employees of the Aviation Sector
}

\author{
Małgorzata Dobrowolska ${ }^{1, *\left(\mathbb{C}, \text { Maria Flakus }^{2} \oplus \text {, Magdalena Ślazyk-Sobol }\right.}{ }^{3}$ and \\ Adam Wawoczny ${ }^{4}$ \\ 1 Institute of Education and Communication Research, Silesian University of Technology, 44-100 Gliwice, \\ Poland \\ 2 Institute of Psychology, University of Silesia, 40-007 Katowice, Poland; flakus.marysia@gmail.com \\ 3 Institute of Psychology, University of Wroclaw, 50-137 Wrocław, Poland; magdalena.slazyk@gmail.com \\ 4 Association of Municipalities and Districts of the Western Subregion, 44-200 Rybnik, Poland; \\ a.wawoczny@subregion.pl \\ * Correspondence: malgorzata.dobrowolska@polsl.pl
}

Received: 15 July 2020; Accepted: 18 August 2020; Published: 23 August 2020

\begin{abstract}
Nowadays, taking into account the multidimensionality of the external environment and necessity of the sustainable development of human resources, organizations are obliged to take more care of the psychological resources of their employees, e.g., positive orientation, ego resilience, and emotional stability. Such resources affect how we cope with stress and a sense of threat. The authors of this paper focus on people employed in the aviation sector, who work in the hard-to-cope environment of full automation, demanding working conditions and numerous stressors. The presented study fills a gap in the research on the psychological characteristics of the aviation sector. Moreover, a sense of stress/threat is described in the context of the high specificity of employees representing the 4.0 sector. Therefore, it provides additional insights into the psychological functioning of the employees in the aviation sector. The results show that both positive orientation and ego resilience might be seen as protective factors against a sense of threat and stress, while a type D personality is a risk factor of a higher level of those psychological states. The novelty of the presented research concerns a better understanding of the sense of stress/threat experienced by the employees in this sector, as well as verifying the relationships between psychological variables described in the literature as personal resources.
\end{abstract}

Keywords: sustainable development of individual competences; positive orientation; ego resilience; depressive personality; psychological stress; sense of threat; the aviation sector

\section{Introduction}

The sustainable development of organizations is a significant part of the contemporary trends of Human Resource Management. It requires not only specific attention to the substantive aspects of professional work, but also hard data, and the preservation of management processes. Above all, it means taking care of developing employees' future competences and investing in employee resources. Only sustainable actions can strengthen the ties among the employees and the company and increase their job satisfaction [1-4].

Furthermore, procedures helpful in maintaining the health of employees are an essential ingredient of sustainable development. In this area, particular attention has been paid to working healthily and 
nurturing healthy and motivated employees [5]. One of the main problems related to this issue is the level of the negative affective states experienced at work. Those challenging states may decrease the integration between person and organization and may be particularly severe for people working in high-risk professions, e.g., in the aviation sector. Above all, feelings of stress and threat seem to be especially burdensome in this professional area. Therefore, the identification of factors predisposing the more intense experience of stress and threat is of particular importance, as these are essential for sustainable development in organizations [6].

While discussing the individual determinants of the level of stress and threat, we may choose various theoretical directions, which mainly correspond with the psychology of health and wellbeing. Above all, the intensive development of positive psychology in the 1950s contributed to numerous empirical studies in psychology that set their focus on the identification of relationships between health determinants and individual potentials [7-11].

Ego resilience is just one such theoretical construct [12-14]. It consists of ego resilience and ego control. Ego control covers tendencies to hold back (versus release) emotional and motivational impulses. In turn, ego resilience means to adjust or match a typical manner of control to an individual situation and its requirements, which stands for the balance of this impulsiveness and its inhibition [10-12]. Thus, ego resilience refers to personal capabilities to respond flexibly to changing situational requirements, including stress, conflict, or uncertainty. The word resilience comes from the following Latin words: salire (meaning to spring up) and resilire (meaning to spring back, to return to the previous state). These two terms, resilience and resiliency, are both used in the literature. The first is defined as the process of effectively overcoming negative life situations and phenomena, while the latter stands for an individual's personality characteristics or his/her relatively permanent resource. The authors of this paper make use of the term "ego resilience" following the creators of the Polish tool for studying this variable [13-15]. Most researchers treat ego resilience as a relatively permanent disposition that determines the process of flexible adaptation to ever-changing life requirements. Thus, they see it as a personality trait (ego resilience) which is relevant in the process of coping with both traumatic conditions as well as everyday circumstances $[16,17]$. Individuals characterized by ego resilience are thus able to adapt in an adequate, consistent, and persistent manner to changing living conditions, both by 'tuning' their capabilities and skills as well as by making appropriate usage of particular factors in their environment. On the opposite side, there are people with a so-called "fragile personality" characterized by a low threshold of frustration [18-20]. Such people react to new situations firmly and anxiously. Resilience is related to experiencing positive emotions, which positively influence the assessment of stressful situations (in terms of a challenge), as well as the choice of more effective and situation-specific coping strategies. Furthermore, it is of importance for a given person's health, particularly his or her mental condition.

Positive orientation (theoretical construct) was first defined by G.V. Caprara to be the fundamental feature of personality (in the sense of a permanent trait), reflecting the general tendency to experience life with a positive attitude [21-24]. According to the author, positive orientation is the opposite of depression; it stands for the underlying tendency to perceive, evaluate, and construct life, the future, and oneself positively [25]. It is a kind of inborn, individually determined disposition which lets a given person live a life full of hope and self-confidence [23]. It is worth noting that in statistical terms, positive orientation is a latent variable that explains differences in self-esteem, life satisfaction, and optimism. Moreover, it predicts more variance within the dependent variables (positive and negative affective states, quality of interpersonal relations, and health status) than self-esteem, life satisfaction, and optimism treated separately [26,27]. Other psychological variables close to positive orientation (treated as the inverse of the depressive triad) primarily include personality health potentials (emotional response styles) and personal resources [26,27]. In terms of the psychological conceptualization of a positive orientation to philosophy, it can be described as "the life wisdom", providing a person with a happy life. 
A type D personality, the so-called depressive personality, which was first introduced in the literature by J. Denoletto [28-31], seems to be a theoretical (although also application-based) opposition to positive orientation. A stress personality-the so-called type D personality [32]—consists of two main dimensions treated as relatively permanent personality traits, namely negative emotionality, and social inhibition. People high in negative emotionality tend to experience strong negative emotions, such as anxiety, anger, irritation, hostility. Social inhibition, in turn, is associated with tendencies to refrain from expressing negative emotions and behaviors consistent with such states. Refraining from revealing feelings is undertaken consciously, mainly in social situations, primarily out of fear of disapproval and rejection by other people. As far as the characteristics of people with type $\mathrm{D}$ personality are concerned, they manifest tendencies to get worried and feel tension, blame themselves, and have a low tendency to share their emotions. Type D personalities are associated with such symptoms of psychological stress as a tendency towards depression, difficulties in perceiving and enjoying social support, low self-esteem, a low level of life satisfaction, and feeling exhausted. Such people also get sick more often and experience various types of health problems 836] [32,33].

In turn, a sense of threat is defined by psychologists as experiencing or fearing the effects of potential or real dangers [33]. When faced with specific professional situations, it generates a distinct cognitive and imaginative 'picture' covering the whole experience related to a given workplace. It may include a variety of elements, but it will primarily be related to internal discomfort and concern about potentially dangerous situations at work (e.g., airborne blast, fire, explosion), as well as worries about factual and current threats occurring in daily, routine work. Additionally, the construct defined as "a sense of threat" includes potential actions resulting from avoiding a threat (at the behavioral and cognitive level-e.g., keeping continuous vigilance and watching out for dangerous elements within the work environment). The concept of stress is commonly used to refer to external circumstances, requirements, burdens, challenging situations, etc., or to describe an unpleasant emotional experience, tension, and discomfort [34]. These two ways of understanding stress are reflected in the theoretical propositions and research studies on the subject.

\section{Materials and Methods}

As mentioned in the introduction, the presented research is explanatory in its nature. The testing of a group of airport staff was planned to better understand this specific population representing 4.0 technology. Although the psychological literature explained a lot of the relations between tested variables, the authors' intention was to verify the given relations between significant factors related to work efficacy [9-11] such as experienced stress, level of threat, and personal resources.

This research study aims to verify a series of hypotheses on relationships between the sense of stress/threat and the following independent variables: positive orientation, type D personality, and ego resilience among employees from the aviation sector in Poland and Slovakia. In view of the accomplishment of the research objective, the following research hypotheses were formulated on the grounds of the literature resources:

Hypothesis 1 (H1). A feeling of stress/threat is negatively related to positive orientation and ego resilience in the group of airport staff [22-24].

Hypothesis 2 (H2). A type D personality is positively related to experiencing a higher level of threat and stress by airport staff $[28,29,32]$.

Hypothesis 3 (H3). A positive orientation and ego resilience are the direct, negative predictors of a sense of threat and stress in the aviation sector $[13,22]$.

Hypothesis 4 (H4). A type D personality is a direct, positive predictor of a sense of stress and threat in the aviation sector $[28,29,32]$. 
The studies reported in the square brackets provide a justification of the hypotheses. Figure 1 presents a conceptual model of the relationships between variables.

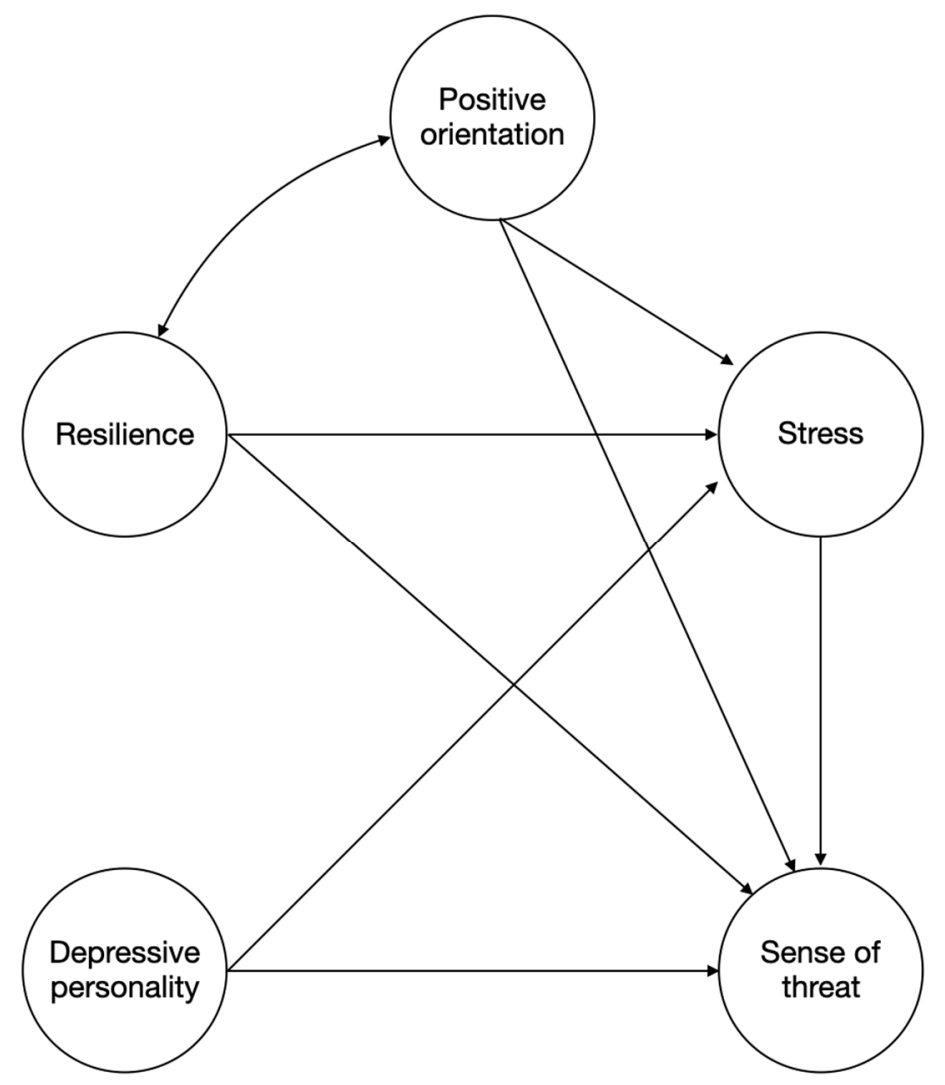

Figure 1. Hypothesized determinants of stress and sense of danger-theoretical model.

\subsection{Sample}

The sample included 326 individuals working in the aviation industry (e.g., airport ground staff, mainly people employed in the range of aircraft apron service, aircraft cabin service, service in the supply of lubricants, fuels and other technical materials, flight operations and administration service, as well as machinery and equipment operators). The exact information about the occupational category of each participant was not collected in the present study. Participants were working at the following airports: Pyrzowice and Szymany (Poland) and Košice (Slovakia). The presented airports are similar when it comes to a comparison of technology issues as well as working conditions and work expectations. People employed at the Polish airports $(n=250)$ were predominant. The remaining group included staff employed at the airport in Košice (Slovakia). All of them were employed under a contract of employment. Their average age was 39.3 years $(\mathrm{SD}=10.7)$. Their overall seniority was 16.7 years on average $(\mathrm{SD}=11.3)$, and their seniority at a given position was 9.0 on average $(\mathrm{SD}=2.5)$. The sample consisted mostly of men ( $n=278 ; 85.3 \%$ ).

When it comes to the ethical aspects of the presented research, all the subjects were notified about the goal of the research, and they voluntarily agreed to participate in the research. Moreover, they had the opportunity to decline to participate and to withdraw from the research once it had started. Additionally, formal approval from the employers managing the airports was obtained. While conducting the study, we followed the recommendations of the Declaration of Helsinki.

The amount of missing data was not greater than $0.5 \%$. All the missing data were excluded from the analysis and not included in the sample size reported above. An additional analysis of the distribution plots suggested the absence of the outliers in the sample. 


\subsection{Materials}

\subsubsection{Positive Orientation}

The Positivity Scale [26] by Caprara et al. was applied to measure the level of positive orientation. The scale consists of eight statements. We used the Polish translation and adaptation of the original questionnaire made by Łaguna, Oleś, and Filipiuk [35]. Every respondent is asked to indicate to what extent he or she agrees with each of the statements. Answers are given on a 5-point scale (1-I strongly disagree; 5-I strongly agree; example item: "I look to the future with hope and enthusiasm"). The results are the total sum of all points: the higher the score, the higher the level of positive orientation. The psychometric development of the tool proves its satisfactory validity and reliability.

In this study, the scale had a satisfactory reliability $(\alpha=0.74)$.

\subsubsection{Ego Resilience}

The SPP-25 ego resilience scale is intended for adults, both healthy and ill persons. It contains 25 statements on a variety of personality traits that make up resilience, also identified as mental resiliency. Answers are given on a 5-point scale ( 0 -definitely not, 4 -definitely yes). The questionnaire measures the following five subfactors: perseverance and determination in action; openness to new experiences and sense of humor; personal coping competencies and tolerance of negative emotions; tolerance of failures and treating life as a challenge; optimistic attitude to life and abilities to be mobilized in challenging situations [16].

In this study, the scale had a satisfactory reliability (perseverance and determination in action: $\alpha=0.73$; openness to new experiences and sense of humor: $\alpha=0.73$; personal coping competences and tolerance of negative emotions: $\alpha=0.71$; tolerance of failures and treating life as a challenge: $\alpha=0.78$; optimistic attitude to life and abilities to be mobilized in difficult situations: $\alpha=0.74$ ).

\subsubsection{Type D Personality}

The D-14 scale for measuring Type D personality by Ogińska-Bulik and Juczyński [32] is a self-description tool. It contains 14 statements, 7 of which relate to tendencies to experience various negative emotions (anxiety, anger, worry, irritation, depression) and 7 to the ability to refrain from expressing such states, mainly in social situations. The surveyed people were asked to assess their personality on the 5-point scale from 0 (no) to 4 (yes). In this study, the scale had a satisfactory reliability (negative emotionality: $\alpha=0.87$; social inhibition: $\alpha=0.86$ ).

\subsubsection{Sense of Threat}

Furthermore, the Feeling of Threat at Work Questionnaire by Mamcarz [33] was applied in the survey. The scale measures a sense of threat comprehended as having concerns about the effects of current/potential dangers at work. It consists of 54 statements evaluated on a 5-point Likert scale (1-never, 5-very often; example item: "When I'm at work, it's difficult for me to concentrate on anything"). It lets us measure the following three factors: internal discomfort, concerns about current risks, and striving to avoid risks.

In this study, the scale had a satisfactory internal consistency (full scale: $\alpha=0.96$; internal discomfort: $\alpha=0.95$; concerns about current threats: $\alpha=0.86$; striving to avoid danger: $\alpha=0.71$ ).

\subsubsection{Sense of Stress}

The Stress Perception Questionnaire by Plopa and Makarowski [34] was applied to measure the level of stress. This scale consists of 27 items rated on a 5-point Likert scale (1-definitely false, 5-definitely true; example items: "I feel the anxiety that more and more things annoy me"). Items in the questionnaire form three scales. The first of them is emotional tension, which refers to experiencing high anxiety, uncertainty, intense fatigue, and the exhaustion of resources. The next subscale measures a 
level of external stress defined as experiencing stress in situations that exceed personal capabilities (e.g., inadequate tasks, work area), but also feeling unfairly assessed and accounted for by others, as well as feeling helplessness and loneliness. The third dimension refers to a level of intrapsychic stress, which is expressed by a lack of ability to cope with negative emotional states. This scale expresses pessimism and a negative perception of oneself/the world outside. The original questionnaire also contains a subscale measuring the tendency to fake positivity. However, the scores obtained in that scale were not analyzed in the present study. There were three reasons for this decision. First, this subscale does not provide any information about the level of stress experienced by a particular person. Second, our study was anonymous. Therefore, we predicted that there were limited concerns that participants would be determined to fake positivity. Finally, the results of the participants were average and suggested a typical, non-pathological tendency of faking positivity.

In this study, the scale had a satisfactory reliability (full scale: $\alpha=0.85$; emotional tension: $\alpha=0.76$; external stress: $\alpha=0.70$; intrapsychic stress: $\alpha=0.73$ ).

\subsection{Data Analysis}

To verify the hypotheses, we used several types of statistical data analyses. First, we provided descriptive statistics (means, medians, and standard deviations) to describe the results. Because of the relatively large sample size, we decided to check the normality using skewness and kurtosis to avoid false-positive results in the traditionally applied normality tests. The results show that all variables had a skewness and kurtosis between -2.0 and +2.0 . Hence, we calculated the Pearson's correlation coefficient to verify the relationships between the variables.

Next, we used structural equation modeling (SEM) to verify the relationships between the variables. SEM is a multivariate statistical analysis technique, in which structural relationships between variables are analyzed. One of the advantages of this technique is the fact that it allows us to predict the values of more than one dependent variable. Besides, it enables us to observe the covariances between given predictive variables. These features make SEM a more appropriate alternative for traditional regression models. Moreover, SEM allows us to put together measured variables with latent constructs. In this case, latent factors are understood as a joint combination of several observed variables. Therefore, it provides a valuable alternative to sum scores because it allows us to catch the relationship between the latent construct and its indicators (e.g., items of the questionnaire, or its subscales).

In the presented model, a series of latent factors were set up for the various dimensions forming resilience, stress, the feeling of threat, and type D personality. Due to a large number of variables, it was decided that we would reduce the detailed dimensions of the analyzed variables to more general latent variables: the sense of threat, the feeling of stress, depressive personality, and resilience. For this purpose, SEM was applied to analyze the relationships between a substantial number of variables. Therefore, it helps to test the theoretical models assumed in the hypotheses.

We used the maximum likelihood method (ML) to estimate the model parameters. This method is the most frequent choice to evaluate the values of the model parameters (e.g., regression weights) for continuous variables. However, the classical accounts of the foundations of ML estimation rely on multivariate normality assumptions. Nevertheless, as stated above (regarding correlation analysis), we decided not to check the normality using traditionally applied methods (e.g., the Shapiro-Wilk test) because of the relatively large sample size. In such cases, long-established normality tests tend to be false positive even in terms of normally distributed variables. Therefore, to check this assumption, we computed the skewness and kurtosis of the variables. The results show that all variables had a skewness and kurtosis between -2.0 and +2.0 . Hence, we assumed that using ML is justified.

\section{Results}

Descriptive statistics for the variables included in the analysis are provided in Table 1. 
Table 1. Positive orientation, mental resilience, depressive personality, sense of threat and feeling of stress-descriptive statistics.

\begin{tabular}{|c|c|c|c|c|c|c|}
\hline & & Mean & Median & $\begin{array}{l}\text { Standard } \\
\text { Deviation }\end{array}$ & Skewness & Kurtosis \\
\hline $\begin{array}{l}\text { Positive } \\
\text { orientation }\end{array}$ & Positive orientation & 29.4 & 30.0 & 3.69 & -0.57 & 0.52 \\
\hline \multirow{5}{*}{$\begin{array}{l}\text { Ego } \\
\text { resilience }\end{array}$} & Perseverance and determination in action & 14.4 & 15.0 & 2.63 & -0.81 & 1.16 \\
\hline & Openness to new experiences and sense of humor & 14.6 & 15.0 & 2.82 & -0.90 & 1.04 \\
\hline & $\begin{array}{c}\text { Personal competences in coping with } \\
\text { negative emotions }\end{array}$ & 14.2 & 15.0 & 2.79 & -0.70 & 0.59 \\
\hline & $\begin{array}{c}\text { Tolerance of failures and treating life as } \\
\text { a challenge }\end{array}$ & 14.5 & 15.0 & 2.98 & -0.88 & 0.89 \\
\hline & $\begin{array}{l}\text { Optimistic attitude to life and capabilities to be } \\
\text { mobilized in difficult situations }\end{array}$ & 14.4 & 15.0 & 2.82 & -0.66 & 0.52 \\
\hline \multirow{2}{*}{$\begin{array}{l}\text { Type D } \\
\text { personality }\end{array}$} & Negative emotionality & 19.4 & 20.0 & 4.89 & -0.66 & 0.03 \\
\hline & Social inhibition & 19.2 & 20.0 & 4.51 & -0.54 & -0.20 \\
\hline \multirow{4}{*}{$\begin{array}{l}\text { Sense of } \\
\text { threat }\end{array}$} & Generalized sense of threat & 108.0 & 104.0 & 25.30 & 1.02 & 1.60 \\
\hline & Internal discomfort & 71.9 & 71.0 & 18.50 & 0.78 & 1.09 \\
\hline & Concerns about current threats & 22.9 & 22.0 & 6.13 & 1.08 & 1.66 \\
\hline & Striving to avoid risks & 13.5 & 13.0 & 3.44 & 0.61 & -0.15 \\
\hline \multirow{4}{*}{$\begin{array}{l}\text { Sense of } \\
\text { stress }\end{array}$} & Generalized sense of stress & 53.8 & 54.0 & 8.95 & -0.54 & 0.52 \\
\hline & Emotional tension & 17.6 & 18.0 & 3.44 & -0.32 & 1.18 \\
\hline & External stress & 18.3 & 18.0 & 3.35 & -0.26 & -0.17 \\
\hline & Intrapsychic stress & 18.0 & 18.0 & 3.83 & -0.38 & -0.03 \\
\hline
\end{tabular}

In order to verify the relationships between the variables, Pearson's correlation coefficients were calculated. The results of the analysis are presented in Table 2. Correlation coefficients with $p<0.05$ were considered as statistically significant.

Table 2. Relationships between positive orientation, resilience and depressive personality and feelings of stress and sense of threat-Pearson's r correlation coefficients.

\begin{tabular}{ccccccccc}
\hline & SD & SD1 & SD2 & SD3 & SS & SS1 & SS2 & SS3 \\
\hline PO & $-0.31^{* * *}$ & $-0.31^{* * *}$ & $-0.24^{* * *}$ & $-0.14^{*}$ & $-0.32^{* * *}$ & $-0.32^{* * *}$ & $-0.18^{* *}$ & $-0.31^{* * *}$ \\
SPP1 & $-0.2^{* * *}$ & $-0.2^{* * *}$ & $-0.26^{* * *}$ & $-0.21^{* * *}$ & $-0.40^{* * *}$ & $-0.40^{* * *}$ & $-0.23^{* * *}$ & $-0.37^{* * *}$ \\
SPP2 & $-0.34^{* * *}$ & $-0.34^{* * *}$ & $-0.27^{* * *}$ & $-0.19^{* * *}$ & $-0.44^{* * *}$ & $-0.39^{* * *}$ & $-0.32^{* * *}$ & $-0.39^{* * *}$ \\
SPP3 & $-0.30^{* * *}$ & $-0.28^{* * *}$ & $-0.27^{* * *}$ & $-0.20^{* * *}$ & $-0.38^{* * *}$ & $-0.37^{* * *}$ & $-0.24^{* * *}$ & $-0.35^{* * *}$ \\
SPP4 & $-0.28^{* * *}$ & $-0.26^{* * *}$ & $-0.25^{* * *}$ & $-0.20^{* * *}$ & $-0.41^{* * *}$ & $-0.37^{* * *}$ & $-0.28^{* * *}$ & $-0.38^{* * *}$ \\
SPP5 & $-0.24^{* * *}$ & $-0.20^{* * *}$ & $-0.25^{* * *}$ & $-0.19^{* * *}$ & $-0.34^{* * *}$ & $-0.35^{* * *}$ & $-0.23^{* * *}$ & $-0.27^{* * *}$ \\
NE & $-0.22^{* * *}$ & $-0.19^{* * *}$ & $-0.24^{* * *}$ & $-0.18^{* * *}$ & -0.06 & $-0.09^{* * *}$ & $-0.04^{*}$ & -0.03 \\
SI & $-0.21^{* *}$ & $-0.18^{* * *}$ & $-0.21^{* * *}$ & $-0.21^{* *}$ & -0.03 & -0.04 & -0.02 & -0.02 \\
\hline
\end{tabular}

Notes: PO-positive orientation, SPP1—perseverance and determination in action, SPP2—openness to new experiences and sense of humor, SPP3-personal coping competences and tolerance of negative emotions, SPP4-tolerance of failures and treating life as a challenge, SPP5-optimistic attitude to life and capabilities to be mobilized in difficult situations, SD-generalized sense of danger, SD1-internal discomfort, SD2-concerns about current threats, SD3 - striving to avoid danger, SS—generalized sense of stress, SS1—emotional tension, SS2 - external stress, SS3—intrapsychic stress, NE—negative emotionality, SI-social inhibition. ${ }^{*} p<0.05 ;{ }^{* *} p<0.01$; $* * * p<0.001$.

Regarding the first hypothesis, the positive orientation was negatively correlated with general sense of threat $(\mathrm{r}=-0.31 ; p<0.001)$ and its subcomponents: fear and internal discomfort $(\mathrm{r}=-0.31$; $p<0.001)$, concerns about current threats $(\mathrm{r}=-0.24 ; p<0.001)$, and striving to avoid threat $(\mathrm{r}=-0.14$; $p=0.013)$. Similarly, positive orientation was linked to a sense of stress $(r=-0.32 ; p<0.001)$ and its subcomponents: emotional tension $(r=-0.32 ; p<0.001)$, external stress $(r=-0.18 ; p=0.001)$ and intrapsychic stress $(\mathrm{r}=-0.31 ; p<0.001)$.

Furthermore, there was a statistically significant relationship between a sense of threat and components of ego resilience: persistence and determination to action $(\mathrm{r}=-0.29 ; p<0.001)$, openness to new experiences and sense of humor $(\mathrm{r}=-0.34 ; p<0.001)$, personal coping competence and tolerance of negative emotions $(\mathrm{r}=-0.30 ; p<0.001)$, tolerance of failures and treating life as a challenge $(\mathrm{r}=-0.28$; 
$p<0.001)$ and optimistic attitude to life and capabilities to be mobilized in difficult situations $(\mathrm{r}=-0.24$; $p<0.001)$.

Similarly, a level of stress was also related to the ego resilience subcomponents: persistence and determination to action $(\mathrm{r}=-0.40 ; p<0.001)$, openness to new experiences and sense of humor $(\mathrm{r}=-0.44 ; p<0.001)$, personal coping competence and tolerance of negative emotions $(\mathrm{r}=-0.38$; $p<0.001)$, tolerance of failures and treating life as a challenge $(\mathrm{r}=-0.41 ; p<0.001)$, and optimistic attitude to life and capabilities to be mobilized in difficult situations $(\mathrm{r}=-0.34 ; p<0.001)$.

The results are consistent with the results of the research presented by Caprara and colleagues [24-26] and Ogińska-Bulik [17-19]. The studies also confirm the coexistence of such personal resources as positive orientation and ego resilience as crucial for the mental health and wellbeing of an individual $[9,10,36,37]$.

Regarding the second hypothesis, relationships between a sense of threat and both negative emotionality $(\mathrm{r}=0.22 ; p<0.001)$ and social inhibition $(\mathrm{r}=0.21 ; p<0.001)$ were also identified. Correlations with a similar (negative) direction and weak strength were also observed in relation to the components of a sense of threat. Similar relationships were not observed between a sense of stress and depressive personality.

In addition, the analysis of relationships between a sense of threat and stress showed a statistically significant correlation $(\mathrm{r}=0.28 ; p<0.001)$.

The results are also consistent with the previous studies. The results of the research conducted by P. Mamcarz [33] and M. Plopa and M. Makarowski [34] confirm that individuals with an initially high level of both depression and neuroticism are more prone to experiencing a higher level of threat and stress.

Next, structural equation modeling (SEM) was then applied to verify the relationships between the variables. The model, together with fully standardized regression coefficients, is shown in Figure 2. Regression weights with $p<0.05$ were considered as statistically significant.

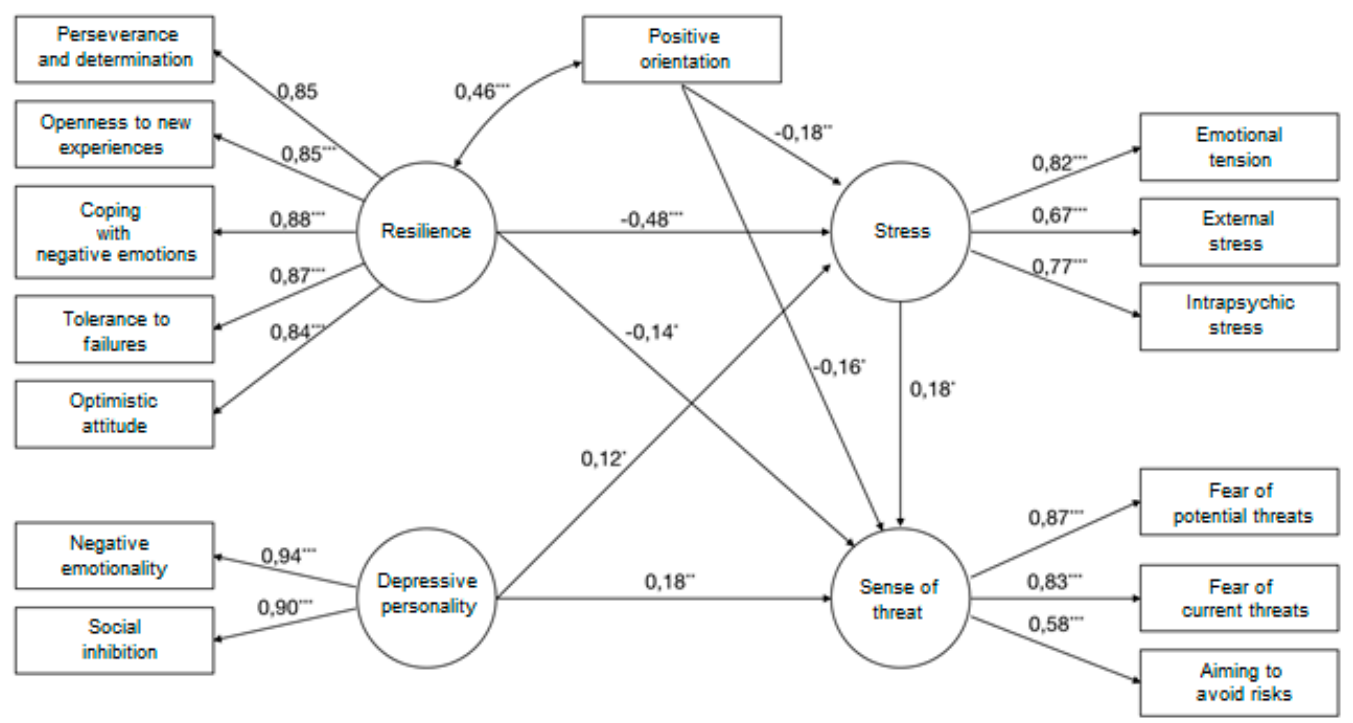

Figure 2. Determinants of stress and sense of danger-structural equation modeling. ${ }^{*} p<0.05$; ${ }^{* *} p<0.01{ }^{* * *} p<0.001$.

The model had a satisfactory fit to the data: The goodness of fit index GFI $=0.94$, Confirmatory Fit Index CFI $=0.97$, Normed fit index NFI $=0.95$, Standardized root mean square residual SRMR $=0.036$, Root mean square error of approximation RMSEA $=0.057,(90 \%$ confidence interval CI: $0.043-0.070)$, $\chi 2(1)=139.33, p=<0.001$.

In this model, resilience was positively related to positive orientation $(\beta=0.46, p<0.001)$. Positive orientation $(\beta=-0.18, p=0.004)$ and resilience $(\beta=-0.48, p<0.001)$ were direct negative predictors 
of stress, while depressive personality $(\beta=0.12, p=0.046)$ was a positive one. The model explained $31 \%$ of the variance for a sense of stress. The presented model is consistent with the results of other psychological studies, and suggest that personal resources such as positive orientation and ego resilience are crucial to minimize the level of perceived stress.

Similarly, positive orientation $(\beta=-0.16, p=0.013)$ and resilience $(\beta=-0.14, p=0.049)$ were direct negative predictors of a sense of threat, while depressive personality $(\beta=0.18, p=0.004)$ and stress level $(\beta=0.18, p=0.023)$ were positive ones. The model explained $21 \%$ of the variance for the sense of threat.

The direct, indirect, and total effects for the variables in the model were presented in Table 3. The analysis indicated that there is a statistically significant indirect effect between resilience, stress, and sense of threat. In this context, a higher level of resilience was associated with a lower sense of stress, which was then related to a lower sense of threat (for the indirect effect: $\beta=-0.08 ; p=0.030$ ). In line with these results, we may assume that in order to protect the wellbeing of an individual, care should be taken to minimize the perceived stress.

Table 3. Direct, indirect and total effects on sense of threat, with sense of stress as mediating variable.

\begin{tabular}{|c|c|c|c|c|c|c|c|c|c|}
\hline Predictor & Estimate & $\mathbf{Z}$ & $p$ & Estimate & $\mathbf{Z}$ & $p$ & Estimate & $\mathbf{Z}$ & $p$ \\
\hline Resilience & -0.14 & -1.99 & 0.046 & 0.08 & -2.17 & 0.03 & -0.23 & -2.34 & $<0.001$ \\
\hline Positive orientation & -0.16 & -2.49 & 0.013 & -0.03 & -1.78 & 0.075 & -0.18 & -3.01 & 0.003 \\
\hline Depressive personality & 0.18 & 2.86 & 0.004 & 0.02 & 1.49 & 0.136 & 0.16 & -2.55 & 0.011 \\
\hline
\end{tabular}

Notes: maximum likelihood estimation was used.

\section{Discussion}

Most of the analyses confirmed the results of the empirical research on personal resources, such as positive orientation, ego resilience, type D personality, and their relationships with psychological stress. The analyzed sample is specific. It includes staff members who have contact with the latest technologies and full automation in their work, and at the same time hold a very high level of responsibility for work on which the efficiency and safety of airport operations depend. Therefore, according to the authors of this paper, the issues of a sense of threat and stress felt at work seem to be relevant for application reasons, but also because of the verification of the previously made theoretical assumptions based on research studies on other, often very different, groups of respondents. The research was considered to be exploratory, taking into account a group of airport staff and testing the research model among this group.

In line with the research, staff members who are full of optimism, hope, and self-confidence, positively oriented towards social contacts, are less often—and to a significantly lower extent—afraid of genuine but also potential threats in their environment and, thanks to this internal strength, they avoid demanding and dangerous situations less often. Similarly, they are less affected by the negative consequences of emotional tension and experienced stressors [36,37]. The results confirm how crucial the role of personal resources is, especially in the case of strengthening mental resilience and, consequently, the general wellbeing of Industry 4.0 employees.

Such traits as perseverance and determination, openness to new experiences and a sense of humor, personal coping competencies and a tolerance of negative emotions, a tolerance of failures and treating life as a challenge, as well as an optimistic attitude to life and the capability to be mobilized in challenging situations significantly reduce the level of psychological stress and the sense of threat. These results confirmed numerous dependencies previously proven in the literature. Similarly, as it might be presumed, negative emotionality and social inhibition turned out to be relevant predictors of a sense of threat. Although the obtained results and SEM models confirm the relationships already known in psychological research, it is worth emphasizing that they have never been studied in a sample of airport staff. Because such employees may be seen as an example of Industry 4.0, the presented 
results may enrich the knowledge about the psychological determinants of negative work-related phenomena such as a sense of stress and a feeling of threat. Moreover, they provide some suggestions about the possible individual risk factors of those states in the everyday work environment.

However, no relationships between depressive personality and a level of experienced stress were proven in this group, which turned out to be quite surprising. In our opinion, the relationship between these variables requires further verification, perhaps taking into account gender-equal study groups. In the case of the presented study, the sample consists mostly of male participants. This may be seen as a limitation of our research. However, it is also important to note that employees in the aviation sector also are predominantly male.

Only the application of more in-depth analyses in the form of a structural equation made it possible to verify the hypotheses more accurately. Due to the multidimensionality of the analyzed variables and the two explained variables (i.e., a sense of stress and threat), structural equation modeling was applied. Based on the developed SEM model, it should be stated that ego resilience, i.e., a "strong", balanced personality and layers of optimism and a positive attitude towards others and the outer world contribute most to the minimization of psychological stress among airport staff members. In turn, inhibiting the expression of negative emotions, suppressing them within oneself, and feeling intense anxiety, anger, and frustration all together generate higher psychological costs in the form of stress. The presented results constitute a valuable hint for practical activities that could support employees of sector 4.0. First of all, they emphasize the importance of soft skills training as a chance for the self-development of employees. Moreover, it may be crucial to provide employees with an opportunity to learn some skills to deal with difficult situations through their adequate expression and unloading. In this case, developing appropriate and effective coping strategies seems to be an important direction in which the level of negative emotions may be regulated.

As far as the determinants of a sense of threat are concerned, in this aspect, positive orientation and ego resilience are also relevant personal resources which inhibit these emotional states, and, in turn, a type $\mathrm{D}$ personality (i.e., traits related to feeling more negative emotions and withdrawing from social interactions) is the factor that leads to the generation of a higher level of threat.

According to the authors, the indirect effect in the form of relationships between "mental resiliency" and stress/a sense of threat deserves special attention. Taking into account the statistical analyses, it should be emphasized that ego resilience-that is, generally speaking, the strength of one's personality, perseverance, tolerance of failures, an optimistic attitude and coping with negative emotions-provides staff employed in the aviation sector with adequate resources to minimize the stress felt, and in the long term reduce any threats experienced, whether these are factual ones encountered in the immediate environment or potential ones which they imagine.

It leads to the conclusion that it is necessary to strengthen and develop their competences to form so-called mental resiliency to minimize the effects of experiencing a state of "threat" in the staff members' psyche. Therefore, there is a need to develop people's determination, capabilities to cope with emerging problems, tolerate frustration, and accept failures. Social relations should be strengthened through greater openness to new experiences and learning to take a positive, hopeful attitude towards the future.

Our results are consistent with the general ideas of the sustainable development of organizations. The sustainable development of an organization implies a certain balance between environmental standards, improving the financial and economic situation of the workplace, while simultaneously taking into account the need to enhance the quality of work for its employees [38], e.g., by giving them an opportunity to develop more beneficial competencies in terms of resiliency, coping, and a positive attitude towards various situations. This idea is not only an idealistic expression of the responsibility towards employees [39], as the resulting implementation of this concept may engender more sustainable development throughout the whole organization and, thus, help the company to achieve its financial and strategic goals $[40,41]$. On the other hand, dealing with employees' distress and promoting strategies facilitating the psychological wellbeing of employees by applying a constructive 
policy in the field of human resource management provide chances for the sustainable development of the company $[42,43]$.

The conducted research studies partly confirmed most of the hypotheses, especially the ones which are well-established in the psychological literature. First of all, H1, on the negative relationship between positive orientation/ego resilience and a sense of stress/threat, was confirmed. As for the second and fourth hypotheses, the link between depressive personality and the threat felt was confirmed. To a lesser extent, depressive personality turned out to be a predictor of psychological stress. "Fragile personality" and low positive orientation have a more significant impact on the level of stress felt. As for the third hypothesis, ego resilience, i.e., mental resiliency, turned out to be the most salient predictor of a sense of threat and stress. The significant indirect effect provided evidence that ego resilience contributes to the minimalization of stress, and, thus, to a reduction in the sense of threat.

These results confirm the role of individual resources in the process of reducing the psychological costs of work in terms of feelings of stress and threat. Taking into account the application perspective, the presented research results indicate the direction of developing specific personal resources (as ego resilience) to enable employees to achieve more sustainable development of their so-called soft skills, but also professional competence, which can be strengthened by better, more predictable functioning in difficult professional situations. On the other hand, the implementation of sustainable practices and technologies brought by the fourth industrial revolution has been globally highlighted [44]—especially whether a given Human Resource Management action based on building cooperative and high-functioning teams can be taken up in Industry 4.0, which is still an exploratory professional field.

\section{Conclusions}

The results of the research emphasize the importance of personality resources in reducing psychological and emotional costs, such as the stress and threat experienced.

However, such research on such deep but also delicate psychological variables has numerous limitations. Above all, the variables presented in the paper cannot be analyzed in any other form than questionnaires. Quantitative surveys addressed to a large number of respondents have the following weaknesses: the averaging of statements made by respondents, a higher tendency to self-present by being a so-called "good respondent" or paying less attention to answering questions in a large number of applied research methods. Due to the non-equivalent segmentation of the surveyed Polish and Slovak airport staff, it was decided that we would not compare the significance of the variance between them in the context of the analyzed variables. The comparison of working conditions, safety standards and the scope of tasks and responsibilities made the grounds for the authors of this paper to adopt an assumption about the similar nature of the work at the three analyzed workplaces.

The results obtained provide valuable, yet simple and clear, application-based guidelines which can be used for the development of staff members at Polish and Slovak airports.

The authors' scientific interest is focused on attitudes, behaviors, and relationships between people employed in the broadly understood context of work 4.0, as well as their professional environment, especially in relation to the latest technologies, automation, and Industry 4.0. Further-already begun-research studies will refer to the adaptation of research tools to this highly specific sector, with a focus on the nature of working conditions in a high-tech environment and the various challenges associated with it.

Author Contributions: Conceptualization, M.D., M.F. and M.Ś.-S.; methodology, M.F.; MŚSsoftware, M.D. and A.W.; validation, M.F., M.Ś.-S. and Z.Z.; formal analysis, M.F.and M.Ś.-S.; investigation, M.D. and A.W.; resources, M.D.; data curation, M.F.; writing—original draft preparation, M.Ś.-S.; writing—review and editing, M.D., M.F. and M.S.-S.; visualization, A.W.; supervision, M.D.; project administration, M.D.; funding acquisition, M.D. All authors have read and agreed to the published version of the manuscript.

Funding: The publication was financed within the framework of the program titled "Dialogue", introduced by the Minister of Science and Higher Education between 2016 and 2019. 
Conflicts of Interest: The authors declare no conflict of interest.

\section{References}

1. Strenitzerová, M.; Achimský, K. Employee satisfaction and loyalty as a part of sustainable human resource management in postal sector. Sustainability 2019, 11, 4591. [CrossRef]

2. Marcos, A.; Pérez-Llantada, M.; Topa, G. Integration in the organizational environment of the Spanish National Police. Sustainability 2019, 11, 4706. [CrossRef]

3. Cho, H.; Lee, P.; Ho Shin, C. Becoming a sustainable organization: Focusing on process, administrative innovation and human resource practices. Sustainability 2019, 11, 3554. [CrossRef]

4. Zhang, Q.; Sun, S.; Zheng, X.; Wei, L. The role of cynicism and personal traits in the organizational political climate and sustainable creativity. Sustainability 2019, 11, 257. [CrossRef]

5. Manuti, A.; Giancaspro, M.L. People make the difference: An explorative study on the relationship between organizational practices, employees' resources, and organizational behavior enhancing the psychology of sustainability and sustainable development. Sustainability 2019, 11, 1499. [CrossRef]

6. Tokarz, A.; Malinowska, D. From psychological theoretical assumptions to new research perspectives in sustainability and sustainable development: Motivation in the workplace. Sustainability 2019, 11, 2222. [CrossRef]

7. Seligman, M.E.; Csikszentmihalyi, M. Positive psychology: An introduction. Am. Psychol. 2000, 55, 5-14. [CrossRef]

8. Fromm, E. Escape from Freedom; Czytelnik: Warsaw, Poland, 1996.

9. Seligman, M.E.P. Can Happiness be Taught? Springer: Cham, Switzerland, 2004.

10. Seligman, M.E.P. Flourish: A Visionary New Understanding of Happiness and Well-Being; Free Press: New York, NY, USA, 2011.

11. Fredrickson, B. The role of positive emotions in positive psychology: The broaden-and build theory of positive emotions. Am. Psychol. 2001, 56, 218-226. [CrossRef]

12. Block, J.H.; Block, J. The Role of Ego-control and Ego-resiliency in the Origination of Behavior. In The Minnesota Symposia on Child Psychology; Collings, W.A., Ed.; Erlbaum: Hillsdale, NJ, USA, 1980.

13. Block, J.; Kremen, A.M. IQ and ego-resiliency: Conceptual and empirical connections and separateness. J. Personal. Soc. Psychol. 1996, 70, 349-361. [CrossRef]

14. Letzring, T.; Block, J.; Funder, D. Ego-Control and ego-resiliency: Generalization of a self-report scales based on personality descriptions from acquaintances, clinicians and self. J. Res. Personal. 2005, 39, 395-422. [CrossRef]

15. Luthar, S.; Cicchetti, D.; Becker, B. The construct of resilience: Critical evaluation and guidelines for future work. Child Dev. 2000, 71, 543-562. [CrossRef] [PubMed]

16. Ogińska-Bulik, N.; Juczyński, Z. SPP 25-Resilience Measurement Scale. Now. Psychoogiczne 2008, 3, 39-55.

17. Ogińska-Bulik, N. Negative and positive effects of emergency staff' traumatic experiences-The role of personal and social resources. Med. Pr. 2013, 64, 463-472.

18. Ogińska-Bulik, N.; Juczyński, Z. Personality traits contributing to somatic diseases development-Role of type D personality. Psychoonkologia 2008, 12, 7-13.

19. Ogińska-Bulik, N.; Juczyński, Z. Personality, Stress and Health; Wydawnictwo Diffin.: Warsaw, Poland, 2008.

20. Uchnast, Z. Personal resilience: Empirical typology and measurement method. Rocz. Filoz. 1997, XLV, $27-49$.

21. Caprara, G.V. Positive orientation: Turning potentials into optimal functioning. Bull. Eur. Health Psychol. 2009, 11, 46-48.

22. Caprara, G.V. Towards the Integration of Traits and Social-cognitive Theory. Contemporary Research on Self-effectiveness: A Modular Approach. In The Colours of Science: Modern ICT for the Dissemination of Scientific Achievements; Nowosada, S., Żurek, B., Eds.; TN KUL: Lublin, Poland, 2010; pp. 315-335.

23. Sobol-Kwapińska, M. Positive orientation-Theoretical concepts and review of research studies. Stud. Psychol. 2014, 52. [CrossRef]

24. Caprara, G.V.; Alessandri, G.; Barbaranelli, C. Optimal functioning: The contribution of self-efficacy beliefs to positive orientation. Psychother. Psychosom. 2010, 79, 328-330. [CrossRef]

25. Caprara, G.V.; Alessandri, G.; Colaiaco, F.; Zuffianň, A. Dispositional bases of self-serving positive evaluations. Personal. Individ. Differ. 2013, 55, 864-867. [CrossRef] 
26. Caprara, G.V.; Alessandri, G.; Eisenberg, N.; Kup-Fer, A.; Yamaguchi, S.; Fukusawa, A.; Steca, P.; Caprara, M.G.; Abela, J.R. The positivity scale. Advance online publication. Psychol. Assess. 2012, 24. [CrossRef]

27. Crumbaugh, J.C.; Maholick, L.T. Manual and Instructions for the Purpose in Life Test, 1981; Psychometric Affiliates: Munster, IN, USA, 1981.

28. Denollet, J. Personality and coronary heart disease: The type D scale-16. Ann. Behav. Med. 1998, 20, $209-215$. [CrossRef] [PubMed]

29. Denollet, J.; Van Heck, G. Psychological risk factors in heart disease. What type D is (not) about. J. Psychosom. Res. 2001, 51, 465-468. [CrossRef]

30. Pedersen, S.; Denollet, J. Type D personality, cardiac events, and impaired quality of life: A review. Eur. J. Cardiovasc. Prev. Rehabil. 2003, 10, 241-248. [CrossRef] [PubMed]

31. Denollet, J.; Sys, S.U.; Stroobant, N.; Rombouts, H.; Gillebert, T.C.; Brutsaert, D.L. Personality as independent predictor of long-term mortality in patients with coronary heart disease. Lancet 1996, 347, 417-421. [CrossRef]

32. Ogińska-Bulik, N. D-Type Personality: Theory and Research; Wyd. WSHE: Łódź, Poland, 2009.

33. Mamcarz, P. Psychology of Threats in High Risk Occupations; WKUL: Lublin, Poland, 2016.

34. Plopa, M.; Makarowski, M. Stress Feeling Questionnaire; Vizja Press \& IT: Warsaw, Poland, 2010.

35. Łaguna, M.; Oleś, P.; Filipiuk, D. Positive orientation and its measurement: Polish adaptation of the positive orientation scale. Stud. Psychol. 2011, 49, 4-47.

36. Czapiński, J. Psychology of Happiness; PTP: Warsaw, Poland, 1994.

37. Czapiński, J. Happiness-Illusion or Necessity? Onion Theory of Happiness in the View of the New Empirical Data. In The Illusions which Let Us Live; Kofta, M., Szustrowa, T., Eds.; PWN: Warsaw, Poland, 2001; pp. 266-306.

38. Oginni, O.S.; Omojowo, A.D. Sustainable development and corporate social responsibility in Sub-Saharan Africa: Evidence from industries in Cameroon. Economies 2016, 4, 10. [CrossRef]

39. Hutchins, M.J.; Sutherland, W. An exploration of measures of social sustainability and their application to supply chain decisions. J. Clean. Prod. 2008, 16, 1688-1698. [CrossRef]

40. Hosseininia, G.; Ramezani, A. Factors influencing sustainable entrepreneurship in small and medium-size enterprises in Iran: A case study of Food Industry. Sustainability 2016, 8, 1010. [CrossRef]

41. Valaskova, K.; Kliestik, T.; Svabova, L.; Adamko, P. Financial risk measurement and prediction modelling for sustainable development of business entities using regression analysis. Sustainability 2018, 10, 2144. [CrossRef]

42. Tutak, M.; Brodny, J.; Dobrowolska, M. Assessment of work conditions in a production enterprise-A case study. Sustainability 2020, 12, 5390. [CrossRef]

43. Carayon, P.; Hundt, A.S.; Karsh, B.-T.; Gurses, A.P.; Alvarado, C.J.; Smith, M.; Brennan, P.F. Work system design for patient safety: The SEIPS model. Qual. Saf. Health Care 2006, 15, 50-58. [CrossRef] [PubMed]

44. Scavarda, A.; Daú, G.; Scavarda, L.F.; Gusmão Caiado, R.G. An analysis of the corporate social responsibility and the Industry 4.0 with focus on the youth generation: A sustainable human resource management framework. Sustainability 2019, 11, 5130. [CrossRef]

(C) 2020 by the authors. Licensee MDPI, Basel, Switzerland. This article is an open access article distributed under the terms and conditions of the Creative Commons Attribution (CC BY) license (http://creativecommons.org/licenses/by/4.0/). 